\title{
FREQUENCY OF OBESE PEOPLE AT HIGH RISK FOR DEVELOPING OBSTRUCTIVE SLEEP APNEA; A CROSS-SECTIONAL SURVEY
}

\author{
Komal Atta ${ }^{\mathrm{a}}$, Raza Ahmad ${ }^{\mathrm{b}}$, Ayesha Nawaz ${ }^{\mathrm{c}}$, Iqra Ishtiaq ${ }^{\mathrm{d}}$, Muhammad Farooq ${ }^{\mathrm{e}}$ \\ ${ }^{a}$ Assistant Director Medical Education, HOD of Dental Education and Senior Coordinator School of \\ Optometry, University Medical \& Dental College, The University of, Faisalabad. \\ ${ }^{b}$ Registrar, Department of Medicine, Ghurkhi Trust Hospital, Lahore. \\ ${ }^{\mathrm{c}}$ Assistant Professor, Services Institute of Medical Sciences, Lahore. \\ 'Post Graduate Resident, Department of Pediatrics, Ganga Ram Hospital, Lahore. \\ 'Senior Medical Officer, THQ Hospital, Kahna.
}

\begin{abstract}
:
BACKGROUND \& OBJECTIVE: Obstructive sleep apnea (OSA) leads to multiple complications which may be life-threatening. In this study we determined the frequency of obese individuals at high risk for developing (OSA).

METHODOLOGY: It was a cross-sectional survey. The study was conducted in the Medicine department of Services hospital, Lahore from February 6, 2016 to August 5, 2016. A sample size of 300 healthy obese individuals (BMI $\geq 30 \mathrm{~kg} / \mathrm{m}^{2}$ ) aged between $18-60$ years who were accompanying a patient or visiting someone admitted, were enrolled in our study. Informed Verbal consent was obtained before administering a structured, validated questionnaire to the significant obese population; Survey was translated into Urdu for ease. The data were stratified for age, gender and BMI of the patients to control the effect modifiers. Post-stratification Chi-square test was used. A p-value $\leq 0.05$ was taken as significant.

RESULTS: A total of 300 subjects were enrolled. Mean age was calculated as $41.81 \pm 11.98$ years, while $161(53.7 \%)$ individuals were females and $139(46.3 \%)$ were males. The frequency of risk of OSA was low in $241(80.3 \%)$ and high in $59(19.7 \%)$ of the population. The relationships of OSA with age groups and BMI were insignificant with $p$-value being 0.867 and 0.790 respectively.

CONCLUSION: In this study, a significant population of male obese individuals was found to be at high risk for obstructive sleep apnea.

KEYWORDS: Obstructive Sleep Apnea, Obesity, Berlin Questionnaire.
\end{abstract}

How to cite this:

doi: https://doi.org/10.37723/jumdc.v11i2.427

Atta K, Ahmad R, Nawaz A, Ishtiaq I, Farooq M. FREQUENCY OF OBESE PEOPLE AT HIGH RISK

FOR DEVELOPING OBSTRUCTIVE SLEEP APNEA. jumdc. 2020;11(3):39-45.

doi: https://doi.org/10.37723/jumdc.v11i2.427

This is an Open Access article distributed under the terms of the Creative Commons Attribution License (http://creativecommons.org/licenses/by/4.0), which permits unrestricted use, distribution, and reproduction in any medium, provided the original work is properly cited. 


\section{INTRODUCTION:}

Obstructive sleep apnea (OSA) also referred to as obstructive sleep apnea-hypopnea syndrome (OSAH Syndrome), is a disorder characterized by frequent episodes of complete or partial upper airway obstruction leading to poor quality of nighttime sleep and excessive daytime somnolence. The ensuing reduction of airflow often leads to episodes of snoring, pauses in breathing, hypoxemia resulting in acute derangements in gas exchange, and recurrent arousals from sleep. Apnea refers to a pause in respiration for more than 10 seconds in obstructive sleep apnea (OSA) ${ }^{[1]}$.

Obstructive sleep apnea involves cessation or significant decrease of airflow in the presence of respiratory effort. There is a repetitive collapse of the upper airway, which may be either partial or total resulting in hypopnea or apnea, respectively during sleep. If it occurs more than five times per hour (apnea-hypopnea index $(\mathrm{AHI})$ ) then it is labeled as OSAHS ${ }^{[2]}$.

The repetitive nocturnal hypoxemia experienced by patients with OSA is associated with activation of several neural, humoral, thrombotic, metabolic, and inflammatory disease mechanisms, all of which have also been implicated in the pathophysiology of various systemic diseases. During this whole process, quality of sleep disturbs, it also leads to sleep deprivation, poor sleep hygiene, and the patient remains lethargic. These effects lead to the individual having excessive daytime somnolence and a feeling of overnight wakefulness ${ }^{[2]}$.

OSA is independently associated with an increased likelihood of multiple complications which may be life-threatening like hypertension, cardiac failure, stroke, atrial fibrillation, diabetes, gastroesophageal reflux disease (GERD), and pulmonary hypertension ${ }^{[3]}$. OSA has now considered in itself a major modifiable risk factor for stroke. OSA causes significant morbidity if not mortality directly, but it can be an indirect contributing factor for increased mortality. It is a source of lost productivity in the workplace and is associated with an increased incidence of motor vehicle accidents, which may be fatal. Obesity is one of the major risk factors for developing it ${ }^{[2]}$.

International studies reported a prevalence of

Corresponding Author:
Dr. Komal Atta
Assistant Director Medical Education,
Sead Department of Dental Education and
University Medical \& Dental College,
The University of, Faisalabad.

diagnosed sleep apnea at $4 \%$ in men and $2 \%$ in women in the western population ${ }^{[4]}$. It has been widely reported in international literature that prevalence is comparatively higher for persons with BMI $\geq 30 \mathrm{~kg} / \mathrm{m}^{2}$ i.e. the obese population. In one study, the prevalence of high risk for OSA was $20.2 \%$ for obese participants ${ }^{[4]}$. The data from Asia is scarce. However, studies report prevalence range between $4.98 \%$ to $27.3 \%$ in different Asian countries, with a male-to-female ratio of $2: 1^{[5]}$. In a hospital-based study of urban men between 35 and 65 years from western India, the prevalence of OSA was $19.5 \%$ and is threefold higher in men as compared to women ${ }^{[6]}$.

With the worldwide obesity epidemic, OSA is becoming more of a matter of concern, as obesity is a major risk factor. Using the WHO classification scheme for Asians, the prevalence of obesity in urban women 25-64 years is alarmingly high, around $40 \%$, and is comparable to figures reported from more industrialized countries ${ }^{[7]}$. OSA needs to be detected early, as consequences of untreated OSA can be potentially serious. By this study, we were able to determine the frequency of obesity that were at high risk for developing OSA and we are hopeful that this will help reduce the risk of complications like stroke, hypertension, and other non-communicable diseases in the obese population in Pakistan.

This study will benefit our poor health care system in cost reduction of diagnosis of sleep apnea and other risks associated with obesity. The results of our data were more or less consistent with other people reporting similar studies, within the limitations we had to face.

\section{METHODOLOGY:}

It was a Cross-Sectional Survey. The study was conducted in the Medicine Department of Services Hospital, Lahore from February 6, 2016 to August 5, 2016. A total of 300 subjects 
fulfilling inclusion criteria (All healthy obese individuals $B M I \geq 30 \mathrm{~kg} / \mathrm{m}^{2}$, individuals of both sexes (males and females) and aged between 18 and 60 years, who accompanied a patient or visited a friend or relative admitted in the hospital) were included.

The exclusion criteria were; individuals not willing to participate in the survey, individuals who have current illness e.g. chest infection, heart failure, liver disease, etc. (except hypertension), individuals came to the hospital for medical advice, or for a surgical procedure, individuals who were on regular follow-up with any physician for an illness or were taking any prescription medication.

The exclusion criteria were strictly applied to avoid any potential effect modifiers. The instrument used for collecting data in the present study was the Berlin Questionnaire. The Berlin Questionnaire is one of the commonest used tools for identifying the risk of obstructive sleep apnea in any particular population ${ }^{[4]}$. It has a sensitivity of $77.3 \%$ and specificity of $23.1 \%$, according to recent studies ${ }^{[8,9]}$. The reason for choosing this questionnaire was its pre-validation, ease of administration and brevity along with good sensitivity.

The BQ was administered by a single person to ensure the uniformity of data collection and to adopt a standardized interviewing. The High risk of OSA was recorded as per operational definition.

All the data collection was in accordance with the principles of Helsinki declaration ${ }^{[10]}$. Before administering the Questionnaire an informed verbal consent was obtained from each individual/guardian. All information including demographics i.e. age, gender, BMI, results of $B Q$ were recorded on a predesigned proforma. The individuals at high risk for OSA were offered treatment as per hospital protocol.

The collected data was entered and analyzed in the computer software SPSS v25.0. The discrete variables like gender and High risk of OSA (BMI> $35 \mathrm{~kg} / \mathrm{m}^{2}$ ) were presented as frequency and percentages. Data were stratified for age, gender, and BMI for effect modifiers. Post-stratification, a Chi-Square test was applied. A p-value $\leq 0.05$ was considered significant.

\section{RESULTS:}

A total of 300 subjects fulfilling the inclusion/exclusion criteria were enrolled to determine the frequency of obese people who were suffering from obstructive sleep apnea. Gender distribution of the patients was done which showed that $161(53.7 \%)$ were females and $139(46.3 \%)$ were males age distribution of the patients was done which shows that $104(34 \%)$ were between $18-38$ years of age, while $196(65.3 \%)$ were between $39-60$ years of age. The mean age was calculated as $41.81 \pm 11.98$ years (Table-I).

Frequency of risk of obstructive sleep apnea was shown to be low in $241(80.3 \%)$ of the study subjects and high in $59(19.7 \%)$ respectively (Table-II). Stratification for frequency of OSA with regards to gender showed that out of 59 positive cases of high risk for OSA, 37 were males, 22 were females, and the P-value was 0.004 , which is significant (Table-III). Stratification for frequency of OSA with regards to age was recorded which showed that out of 59 positive cases of OSA 22 were between 1838 years, 37 were between 39-60 years, pvalue was 0.867 , which is not significant (TableIV).

The patients were stratified with regard to BMI in two categories. The BMI in category 1 was $30.00-35.00 \mathrm{~kg} / \mathrm{m}^{2}$ and category 2 was $36.00-$ $42.00 \mathrm{~kg} / \mathrm{m}^{2}$. Category 1 has total of 238 individuals and out of these 45 was found to be high risk. Category 2 has total of 62 individuals and out of these 14 were high risk. The $p$-value is 0.790 which is not significant (Table-V). The mean \pm S.D BMI of the individuals was $32.85 \pm$ 2.56. Among the study population 66 (22\%) were hypertensive and $234(78 \%)$ were not hypertensive. Stratification for frequency of OSA with regards to blood pressure was recorded which showed that out of the 59 positive cases at high risk for OSA, 32 had diagnosed hypertension, and 27 did not, pvalue was 0.000 , which is significant. 
Table-I: Frequency distribution of gender and age groups.

\begin{tabular}{|c|c|c|c|}
\hline \multirow{2}{*}{ Variables } & Frequency & Percent \\
\hline \multirow{4}{*}{ Gender } & Male & 139 & 46.3 \\
\cline { 2 - 4 } & Female & 161 & 53.7 \\
\cline { 2 - 4 } & Total & 300 & 100.0 \\
\cline { 2 - 4 } Age Groups & $\mathbf{1 8 - 3 8}$ years & 104 & 34.7 \\
\cline { 2 - 4 } & $\mathbf{3 9 - 6 0}$ years & 196 & 65.3 \\
\cline { 2 - 4 } & Total & 300 & 100.0 \\
\hline
\end{tabular}

Table-II: Frequency distribution of risk of Obstructive Sleep Apnea (OSA).

\begin{tabular}{|c|c|c|}
\hline Obstructive Sleep Apnea (OSA) & Frequency & Percent \\
\hline Low risk & 241 & 80.3 \\
\hline High risk & 59 & 19.7 \\
\hline Total & 300 & 100.0 \\
\hline
\end{tabular}

Table-III: Stratification of High risk OSA with respect to Gender.

\begin{tabular}{|c|c|c|c|c|}
\hline \multirow{2}{*}{ Gender } & \multicolumn{2}{|c|}{ High risk OSA } & \multirow{2}{*}{ Total } & p-value \\
\cline { 2 - 4 } & Yes & No & \\
\hline \multirow{3}{*}{ Male } & 37 & 102 & 139 & \multirow{2}{*}{0} \\
\cline { 2 - 4 } & $26.6 \%$ & $73.4 \%$ & $100.0 \%$ & \multirow{2}{*}{0.004} \\
\hline \multirow{2}{*}{ Female } & 22 & 139 & 161 & \\
\cline { 2 - 4 } & $13.6 \%$ & $86.4 \%$ & $300.0 \%$ & \\
\hline \multirow{2}{*}{ Total } & 59 & 241 & $100.0 \%$ & \\
\cline { 2 - 4 } & $19.7 \%$ & $80.3 \%$ & & \\
\hline
\end{tabular}

Table-IV: Stratification of High risk OSA with respect to Age.

\begin{tabular}{|c|c|c|c|c|}
\hline \multirow{2}{*}{ Age Groups } & \multicolumn{2}{|c|}{ High risk OSA } & \multirow{2}{*}{ Total } & \multirow{2}{*}{ p-value } \\
\cline { 2 - 4 } & Yes & No & \\
\hline \multirow{2}{*}{$18-38$ years } & 22 & 82 & 104 & \multirow{2}{*}{0} \\
\cline { 2 - 4 } & $21.2 \%$ & $78.8 \%$ & $100.0 \%$ & \multirow{2}{*}{0.867} \\
\hline \multirow{2}{*}{$39-60$ years } & 37 & 159 & 196 & \\
\cline { 2 - 4 } & $18.8 \%$ & $81.2 \%$ & 300 & \\
\hline \multirow{2}{*}{ Total } & 59 & 241 & $100.0 \%$ & \\
\cline { 2 - 4 } & $19.7 \%$ & $80.3 \%$ & \\
\hline
\end{tabular}


Table-V: Stratification of High risk OSA with respect to BMI.

\begin{tabular}{|c|c|c|c|c|}
\hline \multirow{2}{*}{ BMI } & \multicolumn{2}{|c|}{ High risk OSA } & \multirow{2}{*}{ Total } & p-value \\
\cline { 2 - 4 } & Yes & No & \\
\hline \multirow{2}{*}{$30-35 \mathrm{~kg} / \mathrm{m}^{2}$} & 45 & 193 & 238 & \multirow{2}{*}{0.790} \\
\cline { 2 - 4 } & $18.9 \%$ & $81.1 \%$ & $100.0 \%$ & \\
\hline \multirow{2}{*}{$36-42 \mathrm{~kg} / \mathrm{m}^{2}$} & 14 & 48 & 62 & \\
\cline { 2 - 4 } & $22.5 \%$ & $77.5 \%$ & $300.0 \%$ & \\
\hline \multirow{2}{*}{ Total } & 59 & 241 & $100.0 \%$ & \\
\cline { 2 - 4 } & $19.7 \%$ & $80.3 \%$ & & \\
\hline
\end{tabular}

$\mathrm{p}$-value $<0.05$ is taken to be significant

\section{DISCUSSION:}

As mentioned before the Berlin Questionnaire was chosen for its pre-validation, ease of administration, and brevity along with good sensitivity. However, the downside is that we cannot determine exact frequency values without a practical polysomnogram test. So our current research is just an estimate of the frequency of high-risk patients of obstructive sleep apnea in the obese population and this will serve as a base for further investigative research with techniques such as polysomnography in the individuals who are classified as having at high risk for OSA as its unnecessary to screen the whole population with polysomnography. The cost reduction for a poor health system will be a major benefit.

The overall high-risk OSA percentage in our study subjects was $19.7 \%$. While in the literature it was found to be around $28.2 \%{ }^{[4]}$. The slightly lesser percentages compared to the west in our population is possibly due to dietary differences, genetic differences as well as differences in mean BMI and prevalence of obesity and also a difference in the level of awareness regarding signs and symptoms of obstructive sleep apnea which may have been missed out by the subjects during the interview ${ }^{[11]}$.

Interviewee bias also needs to be taken into account as most of our patients belonged to a socio-economic stratum where they may not adequately be able to explain and describe their symptoms and lack awareness of disease conditions itself.
Our results regarding blood pressure were significant in the high-risk OSA population ( $P$ $<0.001)$. This is in accordance with most studies on OSA, which showed blood pressure as a significant factor. A previous study showed a significant correlation between OSA and hypertension, in a sample Pakistani population $[10,12]$. Similarly, studies carried out on other Caucasian populations revealed similar results where obstructive sleep apnea was shown to be independently related to hypertension ${ }^{[4]}$.

The relation between OSA and age proved to be insignificant in our population $(p=0.867)$ this was in concurrence with previous studies held in Asia. For example, a review of studies from Asia regarding sleep apnea, ${ }^{[13,14]}$ showed no significant correlation to age in 3 different studies. However, most Caucasian studies state increasing age as a risk factor for OSA independently ${ }^{[4]}$. This difference is probably accountable for genetic changes in Asian and Caucasian races.

Our study showed a significant correlation between the male gender and a higher risk for OSA $(p=0.004)$. This finding is consistent with the literature, as multiple studies have shown similar results ${ }^{[4,14,15]}$. Men showed more ventilatory sensitivity to hypercapnia and hypoxia in awake periods as compared to females ${ }^{[16,17]}$. Assuming this variation remains during sleep also, it could be a possible explanation to the higher risk of OSA in males.

During sleep, the ventilatory response is depressed in both genders, causing an increase in $\mathrm{PCO}_{2}$. Arousal at this point may lead to an overshot of ventilation, resulting in hypocapnia 
and possible apnea ${ }^{[18]}$. The incidence of apnea and hypoapnea in both genders during nonrandom (NREM) eyeball movement stages of sleep was seen in various studies ${ }^{[19-21]}$. During NREM sleep in both sexes, they suggested that the variation between males and females in apneic thresholds is an indication of a difference in responses of the respiratory chemoreceptors $^{[22,23] \text {. }}$

\section{CONCLUSION:}

A high risk of obstructive sleep apnea is prevalent in significant number of a male obese individual. It is our hope that this study will pave the way for future research on this issue and also be of practical assistance in early diagnosis of obstructive sleep apnea so that timely treatment may be possible.

\section{ACKNOWLEDGMENT: None}

CONFLICT OF INTEREST: All authors disclose no conflict of interest.

GRANT S UPPORT \& FINANCIAL DISCLOSURES: None.

\section{REFERENCES:}

1. Mbata GC, Chukwuka JC. Obstructive sleep apnea hypopnea syndrome. Annals of Medical and Health Sciences Research. 2012;2(1):74-77. DOI: $10.4103 / 2141-$ 9248.96943 PMID: 23209996

2. Romero-Corral A, Caples SM, LopezJimenez $F$, Somers VK. Interactions between obesity and obstructive sleep apnea: implications for treatment. Chest. 2010;137(3):711-719. DOI: 10.1378/ chest.09-0360 PMID: 20202954

3. Pinto JA, Ribeiro DK, Cavallini AF, Duarte C, Freitas GS. Comorbidities associated with obstructive sleep apnea: a retrospective study. International Archives of Otorhinolaryngology. 2016;20(2):145150. DOI: $10.1055 / \mathrm{s}-0036-1579546$ PMID: 27096019

4. Ho ML, Brass SD. Obstructive sleep apnea. Neurology International. 2011;3(3). DOI: 10.4081/ni.2011.e15 PMID: 22368774

5. Wosu AC, Vélez JC, Barbosa C, Andrade A, Frye $M$, Chen $X$, et al. The relationship between high risk for obstructive sleep apnea and general and central obesity: findings from a sample of Chilean college students. International Scholarly Research Notices. 2014;2014. DOI: 10.1155/2014/ 871681 PMID: 24944841

6. Khazaie H, Najafi F, Rezaie L, Tahmasian M, Sepehry AA, Herth FJ. Prevalence of symptoms and risk of obstructive sleep apnea syndrome in the general population. Archives of Iranian Medicine. 2011;14: 335-338. PMID: 21888458.

7. Watson RR, Suliga E. Nutrition in the Prevention and Treatment of Abdominal Obesity. Nutrition in the Prevention and Treatment of Abdominal Obesity. Elsevier; 2014;39-56.

8. Harrington SA. Relationships of objectively measured physical activity and sleep with BMI and academic outcomes in 8-year-old children. Applied Nursing Research. 2016;26(2):63-70. DOI: 10.1016/j.apnr. 2013.02.001

9. Brito LM, Neiva Leite L, Mônica Nunes Cat C, Boguszewski MC. Association of Cardiorespiratory Fitness and Abdominal Obesity in Full Time Students from Countryside: 3710 Board\# 149 June 4, 800 AM-930 AM. Medicine \& Science in Sports \& Exercise. 2016;48(5S):1035.

10. B Guimaraes A, JQ Costa F, RP Junior O, Fontes W, S Castro M. The amazing world of peptide engineering: The example of antimicrobial peptides from frogs and their analogues. Protein and peptide letters. 2016;23(8):722-737.

11. Beydon N, Aubertin G. Diagnostic criteria for obstructive sleep apnea syndrome. Archives de Pediatrie: Organe Officiel de la Societe Francaise de Pediatrie. 2016;23(4):432-436. DOI: $10.1016 / \mathrm{j}$. arcped.2016.01.002 PMID: 26968302

12. Taj F, Aly Z, Kassi M, Ahmed M. Identifying people at high risk for developing sleep apnea syndrome (SAS): a cross-sectional

JUMDC Vol. 11, Issue 3, July-September 2020 
study in a Pakistani population. BMC Neurology. 2008;8(1):50. DOI. 10.1186/ 1471-2377-8-50

13. Nava-Guerra L, Tran WH, Chalacheva $P$, Loloyan S, Joshi B, Keens TG, et al. Modelbased stability assessment of ventilatory control in overweight adolescents with obstructive sleep apnea during NREM sleep. Journal of Applied Physiology. 2016 Jul 1 ; 121(1):185-97. DOI: 10.1152/ japplphysiol.01081.2015 PubMed 27174926

14. Miller JN, Berger AM. Screening and assessment for obstructive sleep apnea in primary care. Sleep Medicine Reviews. 2015; 29:41-51. DOI:10.1016/j.smrv. 2015.09.005

15. Sun J, Hu J, Tu C, Zhong A, Xu H. Obstructive sleep apnea susceptibility genes in Chinese population: a field synopsis and meta-analysis of genetic association studies. PLoS one. 2015; 10(8): e0135942. DOI:10.1371/journal. pone. 0135942

16. Nield L, Kelly S. Outcomes of a communitybased weight management programme for morbidly obese populations. Journal of Human Nutrition and Dietetics. 2016. DOI: $10.1111 /$ jhn. 12392

17. Varvarigou V, Dahabreh IJ, Malhotra A, Kales SN. A review of genetic association studies of obstructive sleep apnea: field synopsis and meta-analysis. Sleep. 2011;34(11):1461-1468. DOI:10.5665/ sleep.1376

18. Apovian CM. Obesity: definition, comorbidities, causes, and burden. American Journal of Management Care. 2016; 22(7):176-185.

19. Kim NH, Lee SK, Eun CR, Seo JA, Kim SG, Choi KM, et al. Short Sleep Duration Combined with Obstructive Sleep Apnea is Associated with Visceral Obesity in Korean Adults. Sleep. 2013;36(5):723-729 DOI.10.5665/sleep. 2636
20. Kim H, Yun $\mathrm{CH}$, Thomas RJ, Lee $\mathrm{SH}$, Seo HS, Cho ER, et al. Obstructive Sleep Apnea as a Risk Factor for Cerebral White Matter Change in a Middle-Aged and Older General Population. Sleep. 2013; 36(5):709-715. DOI: $10.5665 /$ sleep.2632

21. Nixon GM, Hamilton GS. Does Anyone In Your Family Have Obstructive Sleep Apnea?. Journal of Clinical Sleep Medicine. 2016 Jul 15;12(7):941-942. Doi.10.5664/ jcsm. 5916

22. Silva L, Cunha D, Lopes J, Ramalheira J, Freire M, Novio S, et al. Co-morbidities and sleep apnoea severity. A study in a cohort of Portuguese patients. Revista de Neurologia. 2016;62(10):433-438. PMID: 27149185

23. Saeed O, Shabbir U, Arif AB. Comparative effect of phonophoresis using ibuprofen and methyl salicylate with ultrasound using aqueous gel in pain management due to cervical spondylosis. Journal of University Medical \& Dental College. 2018;9(4):3237.

\section{Authors' Contribution:}

Komal Atta: Study design, manuscript writing and proof reading.

Raza Ahmad: Data collection, analysis and manuscript writing.

Ayesha Nawaz: Data collection, statistical analysis and literature search.

Iqra Ishtiaq: Data collection, analysis and final draft of study.

Muhammad Farooq: Manuscript writing and proof reading.

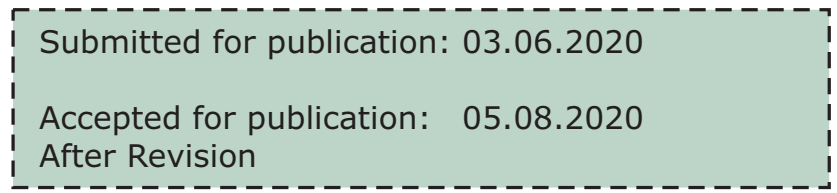

